\title{
COMPORTAMENTO ELEITORAL: RACIONALIDADE, IDENTIDADE E PERSONALISMO NO VOTO EM LULA DA SILVA EM SALVADOR
}

Janaína Xavier do Nascimento

\section{Resumo}

Nesse estudo analisa-se o processo que desencadeou a reeleição de Luiz Inácio Lula da Silva em 2006 com base em estudo de caso realizado com eleitorado da cidade de Salvador, como também em análise de dados secundários. Utilizou-se metodologia qualitativa com dados coletados a partir da técnica de grupos focais. Os resultados apontaram para um eleitor cuja decisão de voto tendeu a se basear numa avaliação racional e retrospectiva de desempenho do governo, estimulada pelo fator identitário e por orientações personalistas.

Palavras-chave: Comportamento eleitoral; Identidade; Personalismo; Racionalidade; Voto.

\begin{abstract}
This study attempts to address the process that culminated in the re-election of Luiz Inácio Lula da Silva in 2006. It is based on a case study carried out in the city of Salvador, Bahia, as well as on analysis of secondary data. We employed a qualitative methodology using data collected through focus groups. Our findings indicate that voters tended to act largely on the basis of rational, retrospective evaluation of government performance, but were also informed by identity issues and personalist tendencies.
\end{abstract}

Keywords: Electoral behavior; Identity; Personalism; Rationality; Voting.

\section{Introdução}

A reeleição de Luís Inácio Lula da Silva, em 2006, instigou intensa discussão acadêmica (CARVALHO, 2006; BAQUERO, 2007; BOHN, 2011; HUNTER e POWER, 2007; SOARES e TERRON, 2008). O debate iniciado arrefeceu, mas as questões sobre a reeleição e seus determinantes seguem propiciando um rico material para aumentar a compreensão do comportamento eleitoral brasileiro. Embora muito se tenha falado sobre o impacto dos programas sociais no resultado daquela eleição, esse aspecto, não obstante ser necessário, está longe de ser suficiente para explicar todo o processo.

No período, viu-se a conjuntura político-eleitoral sofrer oscilações drásticas, de um contexto favorável a um adverso e vice-versa. Como e por que os eleitores brasileiros reelegeram Lula em 2006, ampliando inclusive sua 


\section{DOSSIÊ OPINIÃO PÚBLICA, ELEIÇÕES E PARTICIPAÇÃO POLÍTICA NAS DEMOCRACIAS CONTEMPORÂNEAS}

base de apoio eleitoral? O que essa reeleição revela do comportamento eleitoral brasileiro? Este estudo enfrenta essas questões no intuito de identificar fatores determinantes da reeleição de $L \operatorname{Lula}^{1}$ no âmbito do contexto investigado, qual seja: eleitores da classe $C$ de Salvador (BA). À luz do fato empírico, procura-se discutir algumas de suas implicações teóricas. Tratou-se de um eleitor "racional", "ideológico", "emocional", "intuitivo", "personalista", ou outras características podem ser reveladas?

O tema da reeleição em 2006 gerou vários estudos quantitativos, alguns dos quais referidos mais adiante, entretanto há poucos que incorporam dados qualitativos. Nesse estudo optou-se por explorar a problemática a partir desse trajeto metodológico pouco utilizado, qual seja: a metodologia qualitativa a partir da técnica de grupos focais realizados em Salvador (BA) durante o primeiro e o segundo turnos das eleições de 2006.

Não é novo o uso da técnica dos grupos focais no âmbito das Ciências Sociais (MERTON e KENDALL, 1946; MORGAN e KRUEGER, 1998; FLICK, 2004; GASKELL, 2002; WELLER, 2010). Essa técnica de entrevista teve início em estudos realizados no pós-guerra em pesquisas sobre reação do público à propaganda tendo à frente Robert Merton e Paul Lazarsfeld. Nos últimos anos no Brasil acentuou-se o interesse pelas técnicas de entrevistas em grupo, entre as quais estão situados os grupos focais, utilizados em grande medida em pesquisas psicológicas e antropológicas na área de saúde (WELLER, 2010), mídia, como também em pesquisas político-eleitorais, contribuindo para o mapeamento do perfil de eleitores influenciando assim a definição de diretrizes de partidos políticos e candidatos. Outro uso crescente da técnica de grupos focais compreende a avaliação e redefinição de políticas públicas. A técnica caracteriza-se por grupos formados por um número de seis a dez pessoas que partilham de determinadas características sociodemográficas de modo a formar um grupo internamente homogêneo coordenado por um "moderador" ou "facilitador" guiado por um roteiro de questões semelhantes ao roteiro de uma entrevista semi-estruturada em reuniões com duração aproximada de duas horas. Nesses grupos busca-se apreender processos psicossociais, representações sociais, percepções e atitudes referentes ao tema investigado levando-se em conta a linguagem verbal e não verbal dos entrevistados. O pano de fundo teórico-metodológico a ancorar a técnica baseia-se no interacionismo simbólico, fenomenologia e etnometodologia, sendo um ponto convergente o verstehen como princípio epistemológico (FLICK, 2004).

A composição dos grupos orientou-se por fatores sociodemográficos (sexo, idade, classe social) e atitudinais (intenção de voto). Realizaram-se 20

\footnotetext{
${ }^{1} \mathrm{O}$ impacto da exposição à propaganda política e eleitoral sobre a decisão de voto como fator de curto prazo não se analisará neste estudo pela necessidade de delimitar o escopo de análise. A esse respeito, há estudos recentes, entre os quais: Veiga (2001), Holbrook (apud LAVAREDA, 2009), Lavareda (2009) e Machado (2009). Também mencionada, mas não se analisará, é a tendência à reeleição na América Latina no período (BAQUERO, 2007).
}

REVISTA DEBATES, Porto Alegre, v. 5, n. 2, p. 55-77, jul.-dez. 2011. 
grupos focais no primeiro turno e 12 no segundo. Os grupos eram mistos em relação a sexo, com faixa etária entre 25 e 50 anos e renda enquadrada na classe C (classificação baseada no Critério Brasil). Quanto aos aspectos atitudinais, também eram mistos em relação à intenção de voto. No âmbito dessa investigação não foi possível incluir todas as classes pela necessidade de delimitar seu escopo. A decisão pelo foco analítico na classe $C$ baseou-se principalmente em sua posição majoritária no que concerne ao eleitorado de Salvador (ver Tabela 1).

Por fim, embora a escolha metodológica não possibilite generalizações estatísticas, contribui para compreensão dos processos psicossociais que embasaram a decisão de voto do eleitor da capital baiana. Ademais estudos posteriores podem utilizar os resultados apresentados como hipóteses a serem testadas com vistas a generalizações estatísticas.

Tabela 1 - Distribuição das classes sociais em Salvador (\%)

\begin{tabular}{c|c}
\hline \multicolumn{2}{|c}{ Classes } \\
\hline AB & 10,9 \\
\hline C & 40,1 \\
\hline E & 26,7 \\
\hline Fon & 22,36 \\
\hline
\end{tabular}

Fonte: CPS/FGV a partir dos microdados da PNAD/IBGE (2007).

\section{Parte I - Considerações sobre comportamento eleitoral}

Existem análises detalhadas da produção bibliográfica nacional e internacional sobre comportamento eleitoral (FIGUEIREDO, 1991; CASTRO, 1992; CARREIRÃO, 2002), o que dispensa aqui um levantamento pormenorizado. Observa-se que o debate realizado no Brasil tende a refletir as principais tendências teóricas da literatura internacional, quais sejam: abordagem sociológica - remetida aos trabalhos de Lazarsfeld, Berelson e Gaudet (1944), Lipset e Rokkan (1967) -, abordagem psicossociológica, remetida à Escola de Michigan e aos trabalhos de Campbell et al. (1965), entre outros, e a abordagem da escolha racional (KEY, 1966; FIORINA, 1981; DOWNS, 1999). Também se observa alguns esforços para sintetizar essas abordagens. O fato é que, contemporaneamente, se produziram várias explicações sobre o comportamento eleitoral brasileiro, explicações que, em alguns aspectos, convergem apontando traços similares desse comportamento: baixo grau de informação e de interesse do eleitorado por política, descrédito quanto aos partidos, baixo nível de estruturação ideológica na maioria do eleitorado.

Em outros aspectos, divergem consideravelmente; vide a lista relativamente ampla dos atributos que, segundo seus autores, melhor caracterizam os eleitores brasileiros, ou melhor iluminam seu comportamento - "intuitivo e não racional" (SILVEIRA, 1994), "ideológico" (SINGER, 1998), 


\section{DOSSIÊ OPINIÃO PÚBLICA, ELEIÇÕES E PARTICIPAÇÃO POLÍTICA NAS DEMOCRACIAS CONTEMPORÂNEAS}

"antropológico e não político" (PALMEIRA e GOLDMAN, 1996), "sofisticado" (CASTRO, 1992), "personalista e pragmático" (BAQUERO, 2007), "tipo Flamengo" (REIS, 1988), "racional" (FIGUEIREDO, 1991). Em meio a perspectivas teóricas distintas, um dos aspectos em que se constata maior dissenso é na racionalidade do voto. Nesse sentido, este artigo assume o suposto da racionalidade desde que condicionado pela estrutura, alinhando-se com argumentos já apresentados por Castro (1992). Vejamos como isso pode ser feito.

\section{Voto racional}

A questão da racionalidade da ação e a crítica à onipotência da razão alimentam incessantes debates nas Ciências Sociais. Aqui, a defesa do voto racional não ignora essa discussão, tampouco partilha da crença numa razão onipotente imersa no real e nas interpretações dele. Contudo, como Max Weber mostrou com sua tipologia da ação, a ação racional, seja ela instrumental, seja baseada em valores, está presente na modernidade e nela assume um papel relevante. Nesse sentido, o que significa pensar o processo de decisão de voto como racional?

Segundo Downs (1999, p. 57), "cidadãos agem racionalmente em política", significando que "cada cidadão vota no partido que ele acredita que Ihe proporcionará mais benefícios do que qualquer outro". Os benefícios a que se refere são aqueles resultantes das atividades governamentais: policiamento, tratamento de água, pavimentação, coleta de lixo. No caso do Brasil, devem ser inclusas saúde e educação. Downs (1999, p. 58) explica que "apenas os benefícios dos quais os eleitores se tornam conscientes podem influenciar suas decisões de voto". Tais afirmações remetem à velha discussão sobre concepções hobbesianas ou rousseaunianas dos atores sociais, entretanto, Downs (1999, p. 58) também não estava alheio a ela.

Nessa perspectiva entram nos cálculos do eleitor racional dois períodos eleitorais, aquele que termina no dia da eleição e o que inicia com a eleição. Como o eleitor calcula os benefícios esperados? Comparando o desempenho futuro dos concorrentes, mas, como não é ingênuo, sabe que não pode levar em conta apenas a comparação das plataformas. É preciso estimar o que "realmente fariam se estivessem no poder". Para tanto, o eleitor leva em conta passado, presente e futuro, considerando os benefícios recebidos e aqueles que seriam recebidos se a oposição estivesse no poder. Na avaliação do desempenho futuro, ele considera o fator tendencial - o governo atual está indo bem ou mal? - e avaliações de desempenho, um "julgamento feito sobre a folha de serviços do partido no poder" que remete o eleitor a uma decisão pela continuidade ou pela mudança.

O trabalho de Downs, primeira edição de 1957, tornou-se uma referência importante, fomentando trabalhos ora convergentes, ora hostis a seus argumentos. Apesar das restrições e das debilidades que lhe têm sido 
apresentadas - dificuldade ou impossibilidade de explicar como se formam as preferências partidárias, ou falta de embasamento empírico para a pressuposição de um eleitor informado, interessado e envolvido em política -, seu trabalho é importante por realçar a racionalidade e instrumentalidade do voto.

Buscando superar algumas debilidades da teoria de Downs, o trabalho de Fiorina (1981) demonstrou que, independentemente do grau de informação sobre o processo político, eleitores se posicionam não aleatoriamente por meio do voto em relação à atividade governamental em curso. De modo que, baseado em Downs (1999) e Key (1966), propõe uma teoria do voto retrospectivo em que se articulam fatores de longo prazo (identificação partidária) e fatores de curto prazo (avaliação de desempenho do governo). Ainda em relação à crítica recorrente de que a suposição da racionalidade carrega dentro de si o pressuposto de altos níveis de informação e sofisticação política, é necessário ressaltar: mesmo que o voto seja desinformado ou pautado em equívocos ou falseamento do real, não significa que seja irracional. Em suma, voto racional não pressupõe níveis altos de informação e sofisticação política, mas o caráter instrumental e até certo ponto reflexivo do voto.

Nessa perspectiva a avaliação do desempenho administrativo do governo num sentido retrospectivo e prospectivo assume papel fundamental na decisão de voto, e o estado da economia desempenha um papel extremamente importante. Assim, diante de uma economia em crescimento, o candidato governista tende a obter maior aprovação e ser premiado com o voto como instrumento de continuidade das políticas vigentes. Por outro lado, diante de uma economia estagnada ou recessiva, o candidato governista tende a ser punido com o não voto como instrumento de mudança que favorecerá o candidato oposicionista.

Estudos realizados no Brasil sobre a eleição presidencial de 1989, 1994, 1998 e 2006 (MENDES e VENTURI, 1994; MENEGUELLO, 1995; CARREIRÃO, 2002; RENNÓ e CABELLO, 2010) demonstram o papel central do voto retrospectivo tendo na economia um componente crucial para essa avaliação. Contudo, explicar a reeleição de Lula com base unicamente no voto racional e retrospectivo não basta, uma vez que outros determinantes contribuíram para a escolha eleitoral. É o que se verá a seguir.

\section{Voto mediado pela identidade}

As tentativas de elucidar o conceito de identidade e os processos identitários nele expressos - isto é, a reflexão sobre unidade na diversidade e permanência na mudança - não estão circunscritas a um único campo de conhecimento. Esse conceito tem uma história muito longa, que permeia campos disciplinares distintos como filosofia, psicologia, psicanálise, sociologia, antropologia e, mais recentemente, teoria feminista, estudos 


\section{DOSSIÊ OPINIÃO PÚBLICA, ELEIÇÕES E PARTICIPAÇÃO POLÍTICA NAS DEMOCRACIAS CONTEMPORÂNEAS}

culturais e estudos pós-coloniais.

Neste artigo, o conceito de identidade não se define em sua acepção lógica ou ontológica. A definição aqui reporta-se a Nascimento (2005), privilegia um enfoque sociológico e se nutre do diálogo contemporâneo com a filosofia, a teoria feminista e os estudos culturais. Em contraposição a dimensão cognitivo-racional e essencialista enfatiza a dimensão cultural e relacional das identidades. A relevância atribuída a essas dimensões está presente em tendências teóricas distintas e seus vários autores como Charles Taylor, Manuel Castells, Norberto Elias, Stuart Hall, Chantal Mouffe, entre outros. Taylor (1997) aclara essa dimensão relacional ao remeter aos papéis fundamentais dos interlocutores, das redes de interlocução e da linguagem.

Assim, o conceito de identidade ancora-se nas categorias de identificação, classificação e reconhecimento, como abaixo:

[...] identidade compreende acima de tudo um sentido de pertencimento baseado em identificação, do qual resultam formas de classificação e diferenciação entre o eu e o outro, entre nós e eles, e que não prescinde de reconhecimento. 0 sentimento de pertença a determinados agrupamentos sociais ou comunidades (nacionalidade, raça, gênero, etnicidade, sexualidade) está baseado na partilha de significados produzidos através da identificação e relações de reconhecimento com outros significantes (NASCIMENTO, 2005, p. 26).

A identidade refere-se a uma "compreensão de quem somos, de nossas características definitórias fundamentais como seres humanos", e ainda: "A importância do reconhecimento é agora amplamente reconhecida de uma forma ou outra; [...] todos sabem que a identidade pode ser formada ou mal formada no curso de nosso contato com outros significativos" (TAYLOR, 2000, p. 241, 249).

De forma sintética, pode-se dizer que as identidades têm uma dimensão relacional fundante, isto é, constituem-se por meio da interação com o outro. Esse outro é capaz de reconhecer e de ser reconhecido, mas também de negar ou distorcer esse reconhecimento. É, portanto, uma relação marcada pelo conflito, pelo poder e pela negociação, de maneira que, num processo em que a relação com o outro é fundamental, a categoria reconhecimento assume um lugar de extrema relevância, passando a ser um elemento constitutivo das identidades praticamente inquestionável, sejam elas identidades de gênero, étnicas, nacionais, regionais, sejam outras.

Saindo do plano geral e conceitual da constituição de identidades e localizando a questão no comportamento eleitoral, é oportuno remeter a Reis (1988, p. 36), que, há alguns anos, afirmou: "a identidade está sempre em jogo", seja no comportamento eleitoral brasileiro, seja no americano, no europeu: 
Ela está em jogo 'na síndrome do Flamengo' em que 'os pobres' são contrapostos aos 'ricos' [...], da mesma forma que está em jogo na 'identificação' herdada com Democratas ou Republicanos, nos Estados Unidos, ou na 'identificação' supostamente issue-oriented do trabalhador europeu com este ou aquele partido socialista (REIS, 1988, p. 36, grifos do autor).

Para finalizar este tópico, saliente-se: além da racionalidade do voto, que implica uma avaliação retrospectiva e prospectiva das condições e candidatos apresentados, é possível constatar o papel fundamental do fator identidade que se refere, em boa parte, à capacidade do candidato em criar um elo de identificação com o eleitor.

\section{Voto personalista}

O personalismo político tem sido uma característica bastante enfatizada nos estudos sobre comportamento eleitoral brasileiro, nos quais se enfatiza o declínio do papel dos partidos políticos, uma espécie de "esmaecimento dos laços psicológicos" entre eleitores e partidos (BAQUERO, 2007; LAVAREDA, 1999; MENEGUELLO apud CARREIRÃO e KINZO, 2004; SAMUELS, 2004). Seja remetendo a cultura política brasileira, marcada pelo clientelismo e patrimonialismo, seja remetendo a aspectos institucionais do sistema eleitoral como regras eleitorais que reforçam posicionamentos individualistas dos candidatos, ressalta-se a existência de fraca identificação partidária em contraposição ao personalismo.

Observa-se que a direção do voto da maioria do eleitorado brasileiro não se tem orientado por identificação partidária ou ideológica, e sim pela "pessoa do candidato" ou imagem do candidato. Interessa destacar que esse aspecto do enfraquecimento da identificação partidária tem-se mostrado presente não somente no caso brasileiro, sendo abordado como tendência mundial, naturalmente com taxas diferenciadas nos diferentes contextos culturais e institucionais. Segundo Carreirão e Kinzo (2004, p. 135), no debate internacional estaria havendo "crescente consenso sobre o declínio da importância da identificação partidária na decisão eleitoral".

Quanto à eleição presidencial de 1989, Carreirão (2002, p. 114) observa que "teríamos apenas cerca de $30 \%$ dos eleitores para quem a preferência partidária poderia ter influenciado o voto". Curiosamente, esse percentual volta a aparecer nos anos 2000. Samuels (2004), com base em dados do Eseb de 2002, delineia um quadro do eleitorado brasileiro atentando para sua baixa identificação partidária. Também aí apenas um terço desse eleitorado apresenta preferência partidária, e desses, a maioria expressa preferência pelo PT.

Vários estudos, desde a Escola de Michigan, demonstram que, onde há preferência partidária, observa-se forte relação entre esta e a decisão de 


\section{DOSSIÊ OPINIÃO PÚBLICA, ELEIÇÕES E PARTICIPAÇÃO POLÍTICA NAS DEMOCRACIAS CONTEMPORÂNEAS}

voto. No entanto, como atestam Samuels (2004) e Carreirão (2002), a não manifestação dessa preferência ou identificação partidária tem sido constante e generalizada nas eleições brasileiras.

$\mathrm{Na}$ eleição presidencial de 2006, constataram-se vários aspectos do personalismo político brasileiro (BAQUERO, 2007), não obstante as análises que negam sua relevância na explicação dessa eleição (RENNó e CABELLO, 2010). Um indicador importante desse personalismo é a dissociação entre o desempenho eleitoral de Lula, marcado pela ampliação de sua base de apoio, e o desempenho do PT nas eleições proporcionais, marcado pela redução do percentual de votos obtidos em relação a 2002. Adiante, vê-se que, enquanto o PT foi responsabilizado e punido pelos escândalos de corrupção no governo federal, Lula acabou sendo desvinculado e não responsabilizado pelo escândalo.

Nas eleições de 2006 pode-se afirmar que foi o personalismo que saiu vitorioso, pois, a despeito dos escândalos em que o governo foi envolvido, o presidente Lula conseguiu manter e até aumentar sua base de apoio popular, garantindo um segundo mandato (BAQUERO, 2007, p. 234).

Outro indicador relevante é apresentado no estudo em que se observa o enfraquecimento ainda maior da identificação ideológica e partidária em relação à decisão de voto na eleição presidencial de 2006, provocado por uma "diluição das diferenças ideológicas entre partidos" na percepção dos eleitores, depois do primeiro mandato de Lula (CARREIRÃO, 2007, p. 309). Note-se, ainda, que, em 2006, parte majoritária do eleitorado (60\%) não manifestou preferência por nenhum partido.

\section{Parte II - Reeleição de Lula: confluência de fatores objetivos e subjetivos}

Nas incontáveis interpretações da reeleição apresentadas na mídia, a decisão de voto em Lula foi reiteradamente associada a políticas assistenciais e a algum déficit do eleitor (alienação, desinformação, conivência), como observado por Venturi (2007). Entretanto, essas tentativas de explicação pouco contribuíram para elucidar os fatos. O processo que desencadeou a reeleição de Lula deve ser compreendido por uma confluência de fatores objetivos de ordem macroestrutural e de fatores subjetivos de ordem psicossocial. De maneira geral, não se trata de um voto ideológico (excluindo o voto petista, que, como já mostraram alguns estudos, apresenta forte conteúdo ideológico), intuitivo ou não racional, mas sim um voto pragmático, racional e personalista, condicionado por fatores estruturais (economia e políticas sociais) e subjetivos (identificação). Da articulação desses fatores, evidenciou-se um voto baseado significativamente em racionalidade, identidade e personalismo. É o que se buscará ilustrar agora com base em 
dados dos grupos focais realizados na campanha eleitoral do primeiro e segundo turnos, como também em dados secundários.

Ao ser deflagrada a campanha eleitoral de 2006, o panorama políticoeleitoral estava permeado das incertezas comuns a qualquer processo eleitoral; entretanto, uma delas ocupava bastante espaço na mente dos principais atores políticos: qual seria o real impacto das denúncias de corrupção no governo federal sobre a intenção de voto no então presidente Lula? Contudo, as denúncias e os escândalos ("caso Waldomiro Diniz", "caso mensalão"2 e compra de dossiês, por petistas, sobre candidatos adversários) - mesmo que tenha sido o principal tema da campanha de 2006 de acordo com o Estudo Eleitoral Brasileiro -, não foram suficientes para impedir a reeleição.

Não obstante as graves denúncias, Lula foi eleito no segundo turno com $61 \%$ dos votos válidos contra $39 \%$ de Geraldo Alckmin. Não somente venceu como ampliou sua base de apoio, tendo em relação a 2002 uma diferença de mais de sete milhões de votos. Vale a pena destacar algumas características dessa base de apoio ampliada: concentração nos segmentos de baixa renda, de baixa escolaridade e localizados nas regiões Norte e Nordeste. Observou-se ainda uma migração das bases de apoio das capitais para o interior, municípios menos desenvolvidos, havendo aí muita concordância quanto ao impacto dos programas de transferência de renda, principalmente o Bolsa-Família (HUNTER e POWER, 2007; SOARES e TERRON, 2008). Abaixo seguem os resultados da eleição presidencial de 2006 no primeiro e segundo turno, no Brasil e na cidade de Salvador (ver Tabela 2).

Tabela 2 - Resultados da eleição presidencial em 2006 no Brasil e em Salvador

\begin{tabular}{l|c|c|c|c}
\hline \multicolumn{1}{c|}{ Candidatos } & \multicolumn{2}{c|}{ Salvador } & \multicolumn{2}{c}{ Brasil } \\
\hline Lula & $1^{\circ}$ turno & $2^{\circ}$ turno & $1^{\circ}$ turno & $2^{0}$ turno \\
\hline Alckmin & $68 \%$ & $85 \%$ & $49 \%$ & $61 \%$ \\
\hline & $18 \%$ & $15 \%$ & $42 \%$ & $39 \%$ \\
\hline
\end{tabular}

\section{Voto racional baseado em avaliação de desempenho do governo}

O voto retrospectivo explica, em grande parte, a reeleição, o que vem sendo demonstrado também por outros estudos (RENNó e CABELLO, 2010). Os dados do Eseb de 2006 revelam uma vinculação clara e significativa entre a avaliação do governo federal e o voto. Assim, o voto em Lula aparece fortemente ancorado na avaliação de desempenho do governo, revelando um julgamento da folha de serviços do candidato e uma escolha pela continuidade. Não se tratou de um voto intuitivo, não racional ou emotivo

\footnotetext{
2 Denúncias de compra de apoio legislativo na Câmara dos Deputados envolvendo o nome do principal ministro do governo Lula, o então ministro da Casa Civil, José Dirceu.
}

REVISTA DEBATES, Porto Alegre, v. 5, n. 2, p. 55-77, jul.-dez. 2011. 


\section{DOSSIÊ OPINIÃO PÚBLICA, ELEIÇÕES E PARTICIPAÇÃO POLÍTICA NAS DEMOCRACIAS CONTEMPORÂNEAS}

como defendido por alguns estudos do comportamento eleitoral brasileiro. $\mathrm{O}$ eleitor avaliou os candidatos pelo que tinham feito em sua administração, Lula pelo país e Alckmin por São Paulo. Com base nessa avaliação, estimaram o que poderiam fazer como presidente. Desse modo, foi um voto pragmático e instrumental no qual pesaram fortemente os efeitos da política econômica e das políticas sociais. A aprovação aos programas sociais, o bom momento macroeconômico, o aumento do poder aquisitivo dos segmentos de baixa renda ${ }^{3}$, o aumento do crédito e outros aspectos pontuais como pagamento da dívida externa e atuação da Polícia Federal permeavam o discurso dos eleitores de Lula.

Já houve argumento de que a reeleição deveu-se muito mais ao "vácuo" deixado pela oposição do que às ações efetivas do governo federal (CARVALHO, 2006). Contrariando fortemente esse argumento, observa-se que o desempenho político-administrativo consistiu num dos fatores determinantes para a decisão de voto, revelando uma avaliação racional de condições objetivas. Ao longo da campanha eleitoral no primeiro e no segundo turnos, a aprovação a determinadas ações do governo foi ganhando força em relação à desaprovação da corrupção que estaria perpassando as práticas do governo. Diante da percepção de que seu trabalho não estava concluído, foise fortalecendo um posicionamento em defesa da continuidade. Assim, a preferência por Lula ancorou-se na percepção de que "fez e está tentando fazer", que houve melhoria na vida dos brasileiros e benefícios sociais importantes foram proporcionados à população de baixa renda.

\section{a) Política econômica, crescimento e aumento do consumo}

Em 2006, indicadores econômicos como crescimento do PIB, geração de empregos e aumento do consumo delineavam um quadro favorável ao governo Lula.

No cotejo com o governo Fernando Henrique Cardoso, observa-se crescimento do PIB maior - no primeiro e no segundo mandatos de FHC, respectivamente $2,6 \%$ e $2,3 \%$; e no governo Lula $3,1 \%{ }^{-4}$ e geração de empregos também consideravelmente maior: 797 mil empregos criados nos governos de FHC e 2.464 milhões de empregos no governo Lula ${ }^{5}$ (GOVERNO..., 2006). Outro dado relevante foi divulgado, no fim de 2006, pela Fundação Getúlio Vargas: diminuição da pobreza e aumento da classe C no país, com mobilidade social de 14 milhões de pessoas. Embora muitos eleitores revelassem insatisfação com os níveis de emprego, quando o

\footnotetext{
${ }^{3}$ Segundo alguns analistas econômicos, entre os quais Ricardo Paes de Barros, o crescimento alcançado pelos $20 \%$ mais pobres da população assemelhava-se ao crescimento chinês (DIMENSTEIN, 2006).

${ }^{4}$ Fonte: IBGE divulgado no O Estado de São Paulo em 22 de março de 2007.

${ }^{5}$ Fonte: IBGE divulgado no O Estado de São Paulo em 24 de dezembro de 2006.
} 
comparavam com o governo anterior, tendiam a considerar melhor a situação atual.

Nesse contexto, na campanha, a estratégia da oposição de buscar esvaziar o argumento de crescimento econômico do país, comparando-o com o crescimento superior alcançado por outros países latino-americanos, não foi bem-sucedida. Ora o argumento não passava no quesito inteligibilidade porque se instalava uma barreira entre cognição e experiência -, ora não passava no quesito credibilidade. O argumento largamente defendido pela campanha petista de que "milhares de brasileiros melhoraram de vida" no governo Lula e a pobreza estava diminuindo tendeu a ser aceito pelos eleitores.

Contra o argumento de que o crescimento do país era pouco significativo, eleitores remetiam ao aumento do poder aquisitivo exemplificado pela compra de eletrodomésticos, eletroeletrônicos, carros, motos, celulares e computadores - decorrente de aumento salarial e programas sociais, às condições facilitadas de crédito, às mudanças provocadas por ações de infra-estrutura (ampliação da eletrificação rural, por exemplo), ao pagamento da dívida externa, entre outros.

\begin{abstract}
Antes de Lula, uma pessoa assalariada não tinha condições de ter uma televisão grande em casa, de ter um DVD. No mandato de Lula, ele deu essa condição para muita gente. Hoje até o pipoqueiro pode ter uma televisão de 29 polegadas, e no mandato de Fernando Henrique, celular era coisa de rico e o salário mínimo aumentava 10 reais. Fernando Henrique ficou no governo doze anos! Mas foi Lula quem conseguiu pagar uma dívida que nesses anos todos Fernando Henrique não conseguiu pagar (21/08/2006, 10 Turno, homem, classe C, 49 anos, Salvador).
\end{abstract}

Ressalte-se que não somente a eleição presidencial de 2006 revelou o voto retrospectivo. Outros estudos (CARREIRÃO, 2002; MENEGUELLO, 1995; MENDES e VENTURI, 1994) vêm corroborar o argumento de que o voto racional retrospectivo tem marcado o comportamento eleitoral brasileiro nas eleições presidenciais.

\title{
b) Políticas sociais e o impacto do Programa Bolsa-Família
}

Dentre todos os fatores apontados como responsáveis pela reeleição de Lula, o impacto das políticas sociais, mais especificamente do Programa Bolsa-Família, é um dos mais consensuais (HUNTER e POWER, 2007; SOARES e TERRON, 2008; LAVAREDA, 2009; LÍCIO, RENNÓ e CASTRO, 2009) embora também haja divergências e tentativas de relativizar seu impacto (BOHN, 2011; CARRARO et al. apud LíCIO, RENNÓ e CASTRO, 2009).

No período, esse programa estava implantado nos 26 estados 


\section{DOSSIÊ OPINIÃO PÚBLICA, ELEIÇÕES E PARTICIPAÇÃO POLÍTICA NAS DEMOCRACIAS CONTEMPORÂNEAS}

brasileiros e no Distrito Federal. Instituições internacionais - Banco Mundial, Banco Interamericano de Desenvolvimento e Fundo Monetário Internacional salientaram suas qualidades (LÍCIO, RENNÓ e CASTRO, 2009). No debate que se instaurou, buscou-se avaliar esse impacto tanto com base em dados agregados quanto em dados individuais, encontrando-se resultados semelhantes.

Em meio aos eleitores entrevistados nos grupos focais, emergiam espontaneamente a aprovação e relevância atribuída aos programas sociais do governo federal, e o receio de que tais programas fossem suprimidos ou deixassem de ser prioridade em outra gestão. A melhoria nas condições de vida da população de baixa renda tendia a ser percebida como fato praticamente inquestionável. Ao longo da campanha, críticas ao programa tendiam a ser rechaçadas; e a proposta de maior fiscalização em relação aos beneficiários do programa e uso indevido dos recursos contribuiu para aumentar sua aprovação. Além disso, os Programas ProUni, ProJovem e Luz para Todos reforçavam o posicionamento de aprovação às políticas sociais do governo, que desembocava no discurso em favor da continuidade em detrimento da mudança.

Até agora, eu não tenho o que reclamar do governo de Lula. Ele já fez muitas coisas, principalmente por aquelas pessoas bem pobres; levou luz para muitos lugares, fez o BolsaFamília, que está servindo para muita gente. Tem muita gente que nem dá valor, mas para quem não tem nada... Quem diz que é esmola, quem pensa isso, não sabe o que é passar necessidade. Disseram que o Programa Fome Zero não é realidade. Pode não ser $100 \%$, mas existe, porque eu convivo com pessoas que recebem. Pode ter algum desvio, mas está funcionando e ajuda quem precisa. Lula está fazendo pelo povo o que nunca fizeram por ele (09/10/2006, 20 Turno, homem, classe C, 25 anos, Salvador).

\section{c) A questão ética}

A questão corrente que permeava vários debates consistia em: por que, diante das graves denúncias de corrupção, o eleitor não somente reelegeu Lula como o fez com uma base de apoio ampliada em relação a 2002? Não se pode afirmar que os eleitores desconhecessem as denúncias. Além de estar constantemente na agenda dos principais veículos de comunicação, a corrupção foi o principal tema da campanha eleitoral segundo o Eseb 2006. O estudo realizado por Rennó e Cabello (2010, p. 48) sobre as bases do lulismo apresenta, entre suas hipóteses, a que se segue: "Os eleitores lulistas não se preocupam tanto com avaliações sobre corrupção. Lulistas não consideraram a corrupção um problema nacional, principalmente aqueles que aderiram a Lula apenas em 2006". Tal hipótese teria sido 
respaldada pelo estudo em questão para o qual "lulistas novos", aqueles que não votaram em Lula em 2002 e votaram em Lula em 2006, seriam menos propensos a ver a corrupção como um problema nacional.

Entretanto, o que se viu nos resultados do Eseb 2006 e nas discussões dos grupos focais não chancela essa interpretação. Como se verá, a corrupção era sim percebida como problema nacional, suscitando sentimentos de "incômodo", "decepção", "indignação" e "preocupação". O eleitor que votou em Lula em 2006 não o fez por considerar a corrupção uma questão pouco relevante. Mais uma vez, o Eseb 2006 demonstrou que houve aumento no número de entrevistados que consideravam a corrupção como o principal problema nacional (BAQUERO, 2007, p. 254). Além disso, o desempenho do PT nas eleições proporcionais, marcado pela perda significativa de peso no Congresso em relação a 2002, e a existência do segundo turno depõem contra a ideia de que os eleitores "não se preocuparam tanto com avaliações sobre corrupção" em sua decisão de voto.

A questão ética tendeu a ser resolvida pelo eleitor desvinculando Lula do PT - ministros e outros subordinados de forma específica, e o PT, de forma geral, seriam os verdadeiros responsáveis -, uma desvinculação alimentada pelas estratégias de blindagem da imagem do presidente e pelo personalismo arraigado no comportamento eleitoral.

Segundo estudos da Analítica Consultoria (apud PIMENTEL JÚNIOR, 2007), concordavam com a seguinte afirmação $81 \%$ dos entrevistados: "Falaram, falaram, mas nunca apareceu nenhuma prova de corrupção contra Lula." Outros 77\% concordavam com esta afirmação: "Quando provaram que as pessoas erraram, Lula não hesitou em demiti-las." Todo o debate instaurado durante a crise política repercutiu negativamente na imagem do presidente. Entretanto, esse impacto negativo foi diluindo-se nos meses que se seguiram sob efeito da dissociação da imagem de Lula do PT. A estratégia de blindagem foi mostrando-se eficiente, seja porque estava sobre o estofo da aprovação do desempenho político-administrativo, seja por atributos de imagem de Lula (liderança, empatia, identificação, superação), seja pelo traço personalista forte que perpassa o comportamento eleitoral brasileiro. Assim, na avaliação pragmática de ganhos e perdas, custos e benefícios, os eleitores valeram-se ainda de alguns argumentos para defender a continuidade do governo, entre os quais, o de que "a corrupção não começou ou aumentou neste governo, apenas tornou-se mais visível", e o aumento do combate à corrupção, seria uma das razões para essa maior visibilidade ${ }^{6}$.

Ele é só presidente, não tem poder para tomar todas as decisões. Esse caso do PT surpreendeu até ele mesmo. Lula perdeu credibilidade pelo partido dele, não pelo trabalho, ou pela pessoa dele ou pelo caráter. Então, eu pergunto: se eu

\footnotetext{
${ }^{6}$ Venturi (2007) mostra a evolução das percepções sobre a corrupção e o governo Lula.
} 


\section{DOSSIÊ OPINIÃO PÚBLICA, ELEIÇÕES E PARTICIPAÇÃO POLÍTICA NAS DEMOCRACIAS CONTEMPORÂNEAS}

tenho três elementos do meu lado que não são de confiança, eu vou perder a confiança por causa deles? Aí eu vou ter de dar um jeito de me afastar deles, e muitos saíram. Eu continuo achando que Lula é um bom presidente. Ele precisa agora de mais tempo, porque o brasileiro é muito impaciente (15/09/2006, 10 Turno, homem, classe C, 38 anos, Salvador).

Mesmo com toda essa conversa que tá tendo de mensalão, mas você vê que ele tá fazendo muita coisa pela população. Assim... a elite tá contra ele, mas a população pobre que foi beneficiada com a ajuda que ele deu, com certeza tá tudo a favor dele (16/10/2006, 20 Turno, mulher, classe C, 37 anos, Salvador).

De maneira geral, foi possível delinear algumas das principais linhas de argumentação do eleitor de Lula: 1) "Lula não sabia e foi vítima" da atuação escusa de seus subordinados. Seria culpado de escolher maus assessores e ministros, contudo, mesmo nesse aspecto, sua responsabilidade foi atenuada com base no argumento de que todos estão sujeitos a cometer erros ao escolher amigos e parceiros de trabalho; 2) "Lula sabia do que estava acontecendo no governo, mas pouco podia fazer" contra as práticas endêmicas de corrupção da política nacional; 3) "Lula sabia" e deveria ser em parte responsabilizado. Essa última linha de argumentação estava bem presente no eleitor que não votou em Lula no primeiro turno - o que já foi interpretado como um voto estratégico punitivo (RENNÓ e HOEPERS, 2010) -, mas votou no segundo turno. Nas três linhas, era possível observar a crença generalizada no não envolvimento direto do presidente desembocando no argumento central de defesa: Lula não podia nem devia ser responsabilizado ou punido politicamente, seja porque foi vítima, seja porque pouco podia fazer contra a corrupção endêmica no país. Não poderia ser responsabilizado por um problema que antecedia e possivelmente iria suceder seu governo.

Nesse sentido, o que deveria ser levado mais em conta era "seu trabalho" (desempenho do governo) e seu caráter, e nesses quesitos encontravam razões para reelegê-lo. Já se argumentou que na eleição presidencial de 2006 a questão econômica se sobrepôs à questão ética, todavia, para parte dos eleitores, não havia sequer uma questão ética no que diz respeito ao presidente, porque essa questão estaria centrada no PT e nos demais partidos. Nesse sentido, a corrupção era vista sim como um problema nacional, mas, de tão generalizado e enraizado, não deveria ser determinante na decisão de voto em Lula.

A gente não pode esquecer também que o PT virou um partido gigante. Tem vários tipos de pessoas envolvidas, não é mais aquele partido pequeno. Tem todo tipo de gente, e 
não dá para responsabilizar Lula pela sujeira do partido. De todos, Lula é o menos culpado. Os culpados são todos, menos ele. O pessoal está envolvido, mas ele não, ele tem a cabeça dele tranqüila. Imagine: tem um colégio, tem a diretoria, e o diretor conhece todos os alunos? A casa da gente, que é bem menor que um país, mesmo assim, às vezes a gente não sabe o que está acontecendo. Para mim, até que prove, Lula não foi cúmplice de ninguém. Tudo bem, ele errou quando escolheu as pessoas, mas nada se provou contra ele. E isso aí não é de hoje, já vem de muito tempo (16/10/2006, $2^{\circ}$ Turno, homem, classe C, 50 anos, Salvador).

Em suma, o voto racional retrospectivo, aliado ao personalismo político, permite compreender a reeleição de Lula a despeito da conjuntura política adversa. Quanto ao voto prospectivo, observou-se que o futuro representado por Lula estava menos vinculado à incerteza do que o representado por Geraldo Alckmin. Enquanto o "futuro de Lula" era percebido como mais "pé no chão", mais visível, seguro e próximo, o de Alckmin era visto como "um futuro distante" e "incerto" ("Se o presidente está indo bem, não sei por que mudar com propostas incertas").

Algumas propostas de Alckmin deixa, assim, um pouco de dúvida porque Lula a gente já conhece, já tem algumas coisas que ele já fez e Geraldo Alckmin é uma pessoa que tá chegando agora e é pouco conhecido aqui na Bahia. A gente só tá conhecendo ele agora por causa do programa eleitoral. Lula tá fazendo e a gente tá vendo e o outro não é certo que vai fazer (28/08/2006, 10 Turno, homem, classe C, 48 anos, Salvador).

Alckmin mostrou São Paulo, o que ele fez, mas eu não tava lá, não conheço ninguém que viveu isso, né? Eu só vejo falar... É diferente de Lula. Eu conheço pessoas que têm o ProUni, o Bolsa Família, que conta a história, que passou por isso, por isso e por isso. Então são coisas que tão perto da minha casa (20/09/2006, 10 turno, mulher, classe C, 35 anos, Salvador).

\section{$O$ poder da identidade}

Há alguns anos, o estudo de Albuquerque (1992) atentava para a relevância da identidade na definição de voto, e, mais especificamente, do voto em Lula. Segundo Albuquerque, os resultados da eleição presidencial de 1989 demonstraram que o voto em Lula foi, na maioria, por identificação em 


\title{
DOSSIÊ OPINIÃO PÚBLICA, ELEIÇÕES E PARTICIPAÇÃO POLÍTICA NAS DEMOCRACIAS CONTEMPORÂNEAS
}

oposição ao voto em Collor, que se mostrou mais "pragmático", um voto por expectativa de realização ${ }^{7}$.

Mais recentemente, o trabalho realizado por Balbachevsky e Holzhacker (2004) apresenta alguns dados relevantes referentes às eleições de 1989, 1994, 1998 e 2002. Baseadas neles, as autoras afirmam:

\begin{abstract}
Nas eleições presidenciais selecionadas, as expectativas de desempenho ou o potencial de realizações do candidato de um lado e, de outro, o potencial de representação e de identificação do candidato polarizaram a atenção do eleitor e ajudaram em sua decisão de voto (BALBACHEVSKY e HOLZHACKER, 2004, p. 248).
\end{abstract}

Nos quatro pleitos analisados, a razão de voto em Lula foi mais fortemente associada à identidade que aos demais candidatos (BALBACHEVSKY e HOLZHACKER, 2004). Nessa perspectiva argumentam que "a candidatura Lula, ao longo desses treze anos, mobilizou especialmente o eleitorado que buscava, ao votar, expressar sua identidade com o candidato escolhido" (BALBACHEVSKY e HOLZHACKER, 2004, p. 250).

Tais estudos deixam entrever a força do voto identitário atestada em outras eleições presidenciais e constatada entre as principais razões do voto em Lula. Nisso tudo, há um aspecto importante a ser destacado: o voto em Lula em 1989, 1994 e 1998 foi, em parte, um voto por identificação conforme mostraram os estudos acima, mas nessas eleições, diferentemente de 2006, essa identificação assumia feições mais ideológicas com o voto do eleitor petista. Em 2006, observou-se identificação mais ampla, incluindo a identificação partidária dos petistas, mas também a identificação cultural baseada numa identidade partilhada: a nordestinidade. Neste ponto, vale a pena retornar a Taylor (2000) quando discute "a política do reconhecimento" advogando o caráter crucial do reconhecimento na definição das identidades e como essa necessidade de reconhecimento foi uma das forças propulsoras de vários movimentos sociais e políticos ${ }^{8}$. O que se pôde observar nos grupos focais foi um voto por identificação e reconhecimento, embora não exclusivamente. Diante de um presidente-candidato nordestino, popular e com altos níveis de aprovação de sua gestão, o eleitor nordestino enxergava sua nordestinidade em outro lugar, lugar diametralmente oposto ao pólo negativo no qual a identidade nordestina frequentemente costuma ser localizada: lugar do arcaico e do atraso contraposto ao moderno, do subalterno, da pobreza extrema e altos níveis de analfabetismo, da ausência

\footnotetext{
7 Em outra perspectiva, Machado (2009), analisando as retóricas da reeleição em 1998 e 2006, aponta como esse aspecto foi usado como estratégia de campanha da candidatura de Lula para estabelecer um laço de identidade de Lula com as classes populares.

8 Taylor remete aos movimentos nacionalistas, ao movimento feminista e aos movimentos étnicos.
} 
de orgulho; um lugar de falta. Nesse outro lugar a identidade nordestina estava associada à superação, ao bem-sucedido, ao aprovado nacionalmente, ao reconhecido internacionalmente, ao desenvolvimento, ao crescimento e ao poder. Nesse sentido, o voto em Lula foi também um voto por identificação ("eu me vejo nele", "me reconheço nele", "me orgulho dele") e por reconhecimento (o reconhecimento percebido na implementação das políticas sociais e o reconhecimento esperado nas políticas públicas de um novo governo $)^{9}$.

O que se viu em 2006, nos grupos focais, contribui para a defesa da relevância da categoria identidade no sentido de compreender e explicar o comportamento eleitoral que desencadeou a reeleição e, possivelmente, para lançar luz sobre o processo de decisão de voto em outras eleições. O eleitor nordestino se reconhecia em Lula, e esse reconhecimento e identificação apareciam imbuídos de orgulho pela identidade nordestina frequentemente vinculada ao pólo negativo em relação às demais regiões do país. Na linguagem ("falar como a gente"), na origem social e econômica ("humilde", "pobre"), na origem regional ("ser nordestino" e ter "sangue nordestino") e na condição de migrante nordestino capaz de superar as adversidades, o eleitor da capital baiana se reconhecia em Lula.

Lula veio de família humilde que nem nós e ele olha mais pela população mais humilde. Ele é um homem do povo, um homem que conviveu com os problemas do povo, então ele visa muito a situação do povo. O jeito dele falar é mais parecido com a gente. É assim, olhe: nem ele nem a gente veio da elite como Alckmin (11/09/2006, 10 Turno, mulher, classe C, 46 anos, Salvador).

Taylor (1997) já enfatizou a importância da linguagem na constituição de identidades como meio de interlocução, conversação, apreensão de linguagens de autocompreensão e autodefinição. Nesse sentido, a linguagem verbal e não verbal de Lula reforçavam o elo de identificação com o eleitor e o sentimento de pertencerem às mesmas comunidades definitórias ("pobre", "de classe média baixa", "nordestino" e não ser "da elite"). Eleitores demonstravam sentimentos de orgulho e admiração ao ver que "o presidente vindo do Nordeste não fez feio". Citavam ações de seu governo como feitos não conquistados pelos presidentes antecessores. Enquanto isso Geraldo Alckmin, candidato da oposição, enfrentava um nível alto de desconhecimento e baixa identificação.

Para aqueles eleitores, embora o voto retrospectivo baseado no desempenho político-administrativo fosse determinante, pesava em favor de

\footnotetext{
${ }^{9}$ Do ponto de vista teórico, poderia ser útil uma apreciação do caráter desse reconhecimento: se reconhecimento do igual valor ou da diferença, mas os dados coletados são insuficientes para realizar essa discussão.
} 


\section{DOSSIÊ OPINIÃO PÚBLICA, ELEIÇÕES E PARTICIPAÇÃO POLÍTICA NAS DEMOCRACIAS CONTEMPORÂNEAS}

Lula o voto baseado na identidade. Além de escolher um candidato capaz de realizações (competente ou realizador), tratava-se de escolher um candidato que conhecia e reconhecia as necessidades prioritárias da população. Em alguns eleitores, observava-se a pressuposição de que o candidato era capaz de "sentir o que o povo sente" por já ter vivido experiências semelhantes.

Além de viver e conhecer as necessidades da população, os eleitores enxergavam um desejo genuíno do candidato Lula em atender suas demandas. Uma percepção fortalecida pela avaliação do desempenho do primeiro governo.

Em suma, esses aspectos fomentadores do voto identitário - a origem social de Lula, sua história de vida, o fato de conhecer as condições de vida da população brasileira de baixa renda, o que é ser nordestino e o que é ser migrante nordestino - não seriam condições suficientes para que uma decisão de voto se estabelecesse baseada unicamente na identidade partilhada. No entanto, esses aspectos, somados à avaliação favorável de condições objetivas (economia e políticas sociais), estimularam o voto lulista, forte e generalizado em Salvador.

Por fim, há um aspecto importante a ser observado. Atentar para a centralidade do voto racional retrospectivo não significa que se esteja pressupondo um voto que se deu sem interferência das emoções. Seja no orgulho e entusiasmo por Lula, como observado no voto por identificação, seja no medo da incerteza representada por Alckmin, essas emoções fizeram parte da decisão eleitoral ${ }^{10}$. Entretanto, tais emoções foram, em grande parte, despertadas por condições objetivas percebidas e ponderadas no voto racional. Daí a afirmar que esse tenha sido um voto não racional, intuitivo ou emocional, parece uma tese que se depara com uma sustentação empírica duvidosa no processo que desencadeou a reeleição.

\section{Considerações finais}

Este estudo procurou apontar alguns determinantes da reeleição de Lula em 2006 contrapondo-se a interpretações que buscam explicar o comportamento eleitoral brasileiro como resultante de um voto intuitivo, aleatório, errático e emocional, ou advogando que a reeleição estaria mais vinculada a um "vácuo" deixado pela oposição; ou que o eleitor "não se preocupou" com as denúncias de corrupção, não as considerando problema nacional; ou que a vitória se basearia num déficit dos eleitores; ou que apenas as políticas sociais teriam sido fator determinante. Contrariando essas ideias, observou-se que o eleitor lulista oriundo da classe $C$ e residente na capital baiana tomou sua decisão de voto impulsionado pela avaliação racional

\footnotetext{
10 A dissertação de Pimentel Júnior (2007) procura mostrar, ancorado na tese de inteligência afetiva baseada na psicologia das emoções e neurociência, o entrelaçamento de razão e emoção no voto nas eleições presidenciais de 2006.
} 
e retrospectiva de desempenho do governo, considerando os benefícios socioeconômicos, sendo fortemente estimulado pelo fator identitário e por orientações personalistas. A questão ética foi resolvida pelo eleitor dissociando Lula de seu partido e imputando o ônus dos escândalos ao PT. No âmbito do contexto investigado a lógica do voto nessa eleição pôde ser mais bem compreendida com base na articulação das categorias racionalidade, identidade e personalismo.

Tanto na literatura nacional como na internacional, é possível observar grande quantidade de fatores apontados como determinantes na decisão de voto. Os resultados deste estudo respaldam a corrente que vem enfatizando o papel do voto retrospectivo e prospectivo. Além desse fator, observou-se que o forte elo de identificação estabelecido entre eleitor e candidato exerceu um papel importante na decisão de voto. Por fim, pode ser útil continuar investigando a validade da tríade analítica que se mostrou eficaz para compreender o voto em Lula da Silva em 2006 na capital baiana e na classe investigada.

Agradeço às críticas e sugestões dos revisores da Revista Debates.

Janaína Xavier do Nascimento é Doutora em Sociologia Política pelo PPGSPUFSC e diretora da JN Pesquisa e Consultoria.

E-mail: janainaxn@gmail.com

\section{Referências}

ALBUQUERQUE, José Augusto Guilhon. Identidade, oposição e pragmatismo: uma teoria política do voto. Lua Nova, São Paulo, n. 26, p. 53-79, ago. 1992.

BALBACHEVSKY, Elizabeth; HOLZHACKER, Denilde Oliveira. Identidade, oposição e pragmatismo: o conteúdo estratégico da decisão eleitoral em 13 anos de eleições. Opinião Pública, Campinas, v. 10, n. 2, p. 242-253, out. 2004.

BAQUERO, Marcello. Eleições e capital social: uma análise das eleições presidenciais no Brasil 2002-2006. Opinião Pública, Campinas, v. 13, n. 2, p. 231-259, nov. 2007.

BOHN, Simone R. Social Policy and Vote in Brazil: Bolsa Familia and the Shifts in Lula's Electoral Base. Latin American Research Review, v. 46, n. 1, p. 5479, 2011.

CAMPBELL, Angus; CONVERSE, Philip; MILLER, Warren E.; STOKES, Donald. The american voter. Nova Iorque: John Wiley \& Sons, Inc., 1965. 
CARREIRÃO, Yan de Souza. A decisão de voto nas eleições presidenciais brasileiras. Florianópolis/Rio de Janeiro: Ed. da UFSC/Ed. da FGV, 2002.

. Identificação ideológica, partidos e voto na eleição presidencial de 2006. Opinião Pública, Campinas, v. 13, n. 2, p. 307-339, nov. 2007.

CARREIRÃO, Yan de Souza; KINZO, Maria D'Alva Gil. Partidos políticos, preferência partidária e decisão eleitoral no Brasil 1989-2002. Dados, v. 47, n. 1, p. 131-168, 2004.

CARVALHO Fernando J. C. Da morte política à consagração: indagações sobre o significado da reeleição de Lula. Novos Estudos Cebrap, São Paulo, n. 76, p. 9-15, nov. 2006.

CASTRO, Mônica M. M. Sujeito e estrutura no comportamento eleitoral. Revista Brasileira de Ciências Sociais, São Paulo, v. 7, n. 20, p. 7-19, 1992.

DIMENSTEIN, Gilberto. A explicação do enigma Lula. Folha de São Paulo, São Paulo, Cotidiano, 4 jun. 2006.

DOWNS, Anthony. Uma teoria econômica da democracia. São Paulo: Edusp, 1999.

FIGUEIREDO, Marcus. A decisão de voto. São Paulo: Idesp/Sumaré, 1991.

FIORINA, Morris. Retrospective voting in american national elections. New Haven: Yale University Press, 1981.

FLICK, Uwe. Uma introdução à pesquisa qualitativa. Porto Alegre: Bookman, 2004.

GASKELL, George. Entrevistas individuais e grupais. In: GASKELL, George; BAUER, Martin W. (Orgs.). Pesquisa qualitativa com texto, imagem e som Um manual prático. Petrópolis: Vozes, 2002. p. 64-89.

GOVERNO Lula criou 2.464 milhões de empregos em 4 anos. O Estado de S. Paulo, Cidades, 24 dez. 2006.

HUNTER, Wendy; POWER, Timothy J. Rewarding Lula: executive power, social policy, and the Brazilian elections of 2006. Latin American Politics \& Society, Coral Gables, v. 49, n. 1, p. 1-30, Spring 2007. 
KEY, Valdimer Orlando, Jr. The responsible electorate: rationality in presidential voting, 1936-60. Cambridge, Massachusetts: Cambridge University Press, 1966.

LAVAREDA, Antonio. A democracia nas urnas: o processo eleitoral brasileiro 1945-1964. Rio de Janeiro: Iuperj/Revan, 1999.

2009.

. Emoções ocultas e estratégias eleitorais. Rio de Janeiro: Objetiva,

LAZARSFELD, Paul; BERELSON, Bernard; GAUDET, Helen. The people's choice. New York: Duell, Sloan \& Pearce, 1944.

LÍCIO, Elaine Cristina; RENNÓ, Lucio R.; CASTRO, Henrique Carlos de O. Bolsa família e voto nas eleições presidenciais de 2006: em busca do elo perdido. Opinião Pública, Campinas, v. 15, n. 1, p. 31-54, jun. 2009.

LIPSET, Seymour M.; ROKKAN, Stein. Party systems and voter alignments. New York: Free Press, 1967.

MACHADO, Mônica. A retórica da reeleição: mapeando os discursos dos programas eleitorais (HGPE) em 1998 e 2006. Opinião Pública, Campinas, v. 15 , n. 1, p. 159-189, jun. 2009.

MENDES, Antônio M. T.; VENTURI, Gustavo. Eleição presidencial: o plano real na sucessão de Itamar Franco. Opinião Pública, Campinas, ano 2, v. 2, n. 2, dez. 1994.

MENEGUELLO, Raquel. Electoral Behavior in Brazil: the 1994 presidential elections. International Social Science Journal, London, n. 146, p. 627-642, dez. 1995.

MERTON, Robert; KENDALL, Patricia. The focused interview. The American Journal of Sociology, Chicago, v. 51, n. 6, p. 541-557, may 1946.

MORGAN, David; KRUEGER, Richard A. (Eds.). The Focus Groups kit. Thousand Oaks, CA: SAGE. 1998. 6v.

NASCIMENTO, Janaína Xavier. Para uma teoria da identidade na modernidade: mudanças e permanências à luz do reconhecimento e do feminismo. 2005. 193 f. Tese (Doutorado em Sociologia Política) - Programa de Pós-Graduação em Sociologia Política, Universidade Federal de Santa Catarina, Florianópolis, [2005]. 
PALMEIRA, Moacir; GOLDMAN, Márcio (Eds.). Antropologia, voto e representação política. Rio de Janeiro: Contra Capa, 1996.

PIMENTEL JÚNIOR, Jairo Tadeu. Razão e emoção no voto: o caso da eleição presidencial de 2006. 2007. 128 f. Dissertação (Mestrado em Ciência Política) - Faculdade de Filosofia, Letras e Ciências Humanas, Universidade de São Paulo, São Paulo, [2007].

REIS, Fábio Wanderley. Identidade, política e a teoria da escolha racional. Revista Brasileira de Ciências Sociais, São Paulo, v. 3, n. 6, p. 26-38, fev. 1988.

RENNÓ, Lúcio; CABELLO, Andrea. As bases do lulismo: a volta do personalismo, realinhamento ideológico ou não alinhamento? Revista Brasileira de Ciências Sociais, São Paulo, v. 25, n. 74, p. 39-60, out. 2010.

RENNÓ, Lúcio; HOEPERS, Bruno. Voto estratégico punitivo: transferência de votos nas eleições presidenciais de 2006. Novos Estudos Cebrap, São Paulo, n. 86 , p. $140-161$, mar. 2010.

SAMUELS, David. As bases do petismo. Opinião Pública, Campinas, v. 10, n. 2, p. 221-241, out. 2004.

SILVEIRA, Flávio. Escolha intuitiva: nova modalidade de decisão do voto. Opinião Pública, Campinas, v. 2, n.2, p.61-72, dez. 1994.

SINGER, André. Identificação ideológica e voto no Brasil: o caso das eleições presidenciais de 1989 e 1994. 1998. Tese (Doutorado em Ciência política) Faculdade de Filosofia, Letras e Ciências Humanas, Universidade de São Paulo, São Paulo, [1998].

SOARES, Gláucio Ary Dillon; TERRON, Sônia Luiza. Dois Lulas: a geografia eleitoral da reeleição: explorando conceitos, métodos e técnicas de análise geoespacial. Opinião Pública, Campinas, v. 14, n. 2, p. 269-301, nov.2008. Loyola, 1997.

As fontes do self: a construção da identidade moderna. São Paulo:

TAYLOR, Charles. Argumentos filosóficos. São Paulo: Loyola, 2000.

VEIGA, Luciana. Em busca de razões para o voto: o uso que o homem comum faz do horário eleitoral. 2001. 246 f. Tese (Doutorado em Ciência Política) Instituto Universitário de Pesquisas do Rio de Janeiro, Rio de Janeiro, [2001]. 
DOSSIÊ OPINIÃO PÚBLICA, ELEIÇÕES E PARTICIPAÇÃO POLÍTICA NAS DEMOCRACIAS CONTEMPORÂNEAS

VENTURI, Gustavo. Determinações e significados da reeleição de Lula. In: CONGRESO LATINOAMERICANO DE OPINIÓN PUBLICA WAPOR, 1., 2007, Colonia del Sacramento, Uruguai. Trabalhos apresentados... Colonia del Sacramento: WAPOR, 2007.

WELLER, Wivian. Grupos de discussão: aportes teóricos e metodológicos. In: WELLER, Wivian; PFAFF, Nicolle (Orgs.). Metodologias de Pesquisa Qualitativa em Educação: Teoria e Prática. 1. ed. Petrópolis: Vozes, 2010. p. 54-66.

Texto recebido em 22/08/2011. Aprovado em 15/12/2011. 